ఠ

\title{
Minimizing cardiac surgery risks in a Hepatitis $C$ patient: Changing surgical strategy after evaluation by modern imaging technologies
}

This article was published in the following Dove Press journal:

Therapeutics and Clinical Risk Management

19 May 2009

Number of times this article has been viewed

\author{
Felix Kur' \\ Andres Beiras-Fernandez' \\ Martin Oberhoffer' \\ Konstantin Nikolaou ${ }^{2}$ \\ Calin Vicol' \\ Bruno Reichart ${ }^{\prime}$ \\ 'Department of Cardiac Surgery, \\ ${ }^{2}$ Department of Radiology, University \\ Hospital Grosshadern, Munich, \\ Germany
}

\begin{abstract}
Minimizing operative risks for the surgical team in infectious patients is crucial. We report on a patient suffering from Hepatitis $\mathrm{C}$ undergoing re-operative aortic valve and ascending aorta replacement for aortic aneurysm and paravalvular leakage due to recurrent endocarditis of a Smeloff-Cutter aortic ball prosthesis. Preoperative multi-slice computed tomography and real-time three-dimensional echocardiography proved helpful in changing operative strategy by detecting a previously unknown aortic aneurysm, assessing its extent, and demonstrating the close proximity of the right coronary artery, right ventricle, and the aortic aneurysm to the sternum. Thus, cardiopulmonary bypass was instituted via the femoral vessels, instead of conventionally. Location, morphology, and extent of the paravalvular defect could also be assessed.
\end{abstract}

Keywords: aortic valve replacement, aorta, surgery, risk analysis

\section{Introduction}

Reducing the operative risks in highly infective patients is crucial for the operating team, especially during a reoperation. Modern imaging can help us to decide the surgical strategy for such patients. We report on a patient suffering from Hepatitis C undergoing re-operative aortic valve and ascending aorta replacement for aortic aneurysm and paravalvular leakage due to recurrent endocarditis of a Smeloff-Cutter aortic ball prosthesis.

\section{Case report}

\section{The patient}

The patient was a 43-year-old Russian male who had previously undergone open aortic valvuloplasty for stenosis as a child, mechanical aortic valve replacement in 1982, and re-replacement with a Smeloff-Cutter caged ball prosthesis due to paravalvular leakage in 1983. During the last few years he had experienced recurrent episodes of fever and was treated with different antibiotics. In October 2005, a different antibiotic regimen, including penicillin and cephalosporin for recurrent fever above $40^{\circ} \mathrm{C}$ was ineffective for controlling his infection and resulted in severe neutropenia with a white blood count of 200/ $\mu 1$. Positive blood cultures for Gram-positive cocci were obtained, aortic regurgitation II-III was seen in two-dimensional echocardiography, aortic endocarditis was suspected, and the patient was transferred to our hospital for aortic valve replacement. Antibiotic treatment with ceftazidime, vancomycin, and rifampin was instituted. Hepatitis $\mathrm{C}$ was known since his second aortic valve replacement; the
Correspondence: Andres Beiras-Fernandez Department of Cardiac Surgery, University Hospital Grosshadern, Marchioninistrasse 15, 81377 Munich, Germany

Tel +498970975074

Fax +49897097 1847

Email andres.beiras@med.uni-muenchen.de 
actual virus load was 1.7 million IU/ml. Laboratory work and sonography disclosed major damage of the liver.

\section{Transthoracic 3D-echocardiography}

Echocardiography was performed with a Philips Ie33 sonography machine (Philips Medical Systems, Solingen, Germany). Standard B- and M-Mode measures from the parasternal long- and short-axis as well as from the apical two- and four-chamber view were obtained. Aortic regurgitation jet was graded II-III and highly suspicious for paravalvular of origin. Real-time three-dimensional examination was able to clearly identify a paravalvular round defect in the left coronary circumference, which corresponded exactly to intraoperative findings (Figure 1). Additionally the aortic root measured $4.2 \mathrm{~cm}$ in diameter and consequently multi-slice computed tomography (MSCT) was initiated.

\section{MSCT}

Electrocardiogram (ECG)-gated 64-row MSCT with volume rendering technique (VRT) and three-dimensional reconstruction was done using a Somatom Sensation 64 (Siemens Medical Solutions, Forchheim, Germany). The ascending aorta showed a maximum of $5.2 \mathrm{~cm}$ in diameter beginning directly above the aortic valve and involving the proximal aortic arch. Furthermore the right coronary artery (RCA), the right ventricle (RV), and the aortic aneurysm showed a close proximity to the sternum thus increasing the risk of being damaged when opening the chest (Figure 2).

\section{Operative strategy}

After cannulation of the femoral vessels, cardiopulmonary bypass (CPB) was initiated and the patient cooled down to $18{ }^{\circ} \mathrm{C}$ allowing open distal anastomosis of the proximal aortic arch during circulatory arrest. The chest was opened with the heart unloaded by extracorporeal circulation. During cooling the heart was exposed by sharp dissection, the aorta was crossclamped, excised, and the aortic valve removed and replaced by a $27 \mathrm{~mm}$ Medtronic Advantage aortic valve prosthesis (Medtronic GmbH, Duesseldorf, Germany). A $25 \mathrm{~mm}$ Dacron tube graft was anastomosed to the aorta above the left coronary artery with reimplantation of the RCA. A 10-minute phase of circulatory arrest allowed for safe distal anastomosis of the Dacron tube to the proximal aortic arch. After thorough deairing of the aorta and the left ventricle, cross-clamping was removed (after 109 minutes), rewarming was started and appropriate reperfusion time was allowed. Decannulation, after 220 minutes of CPB, and closure of the chest and groin were uneventful. Total time

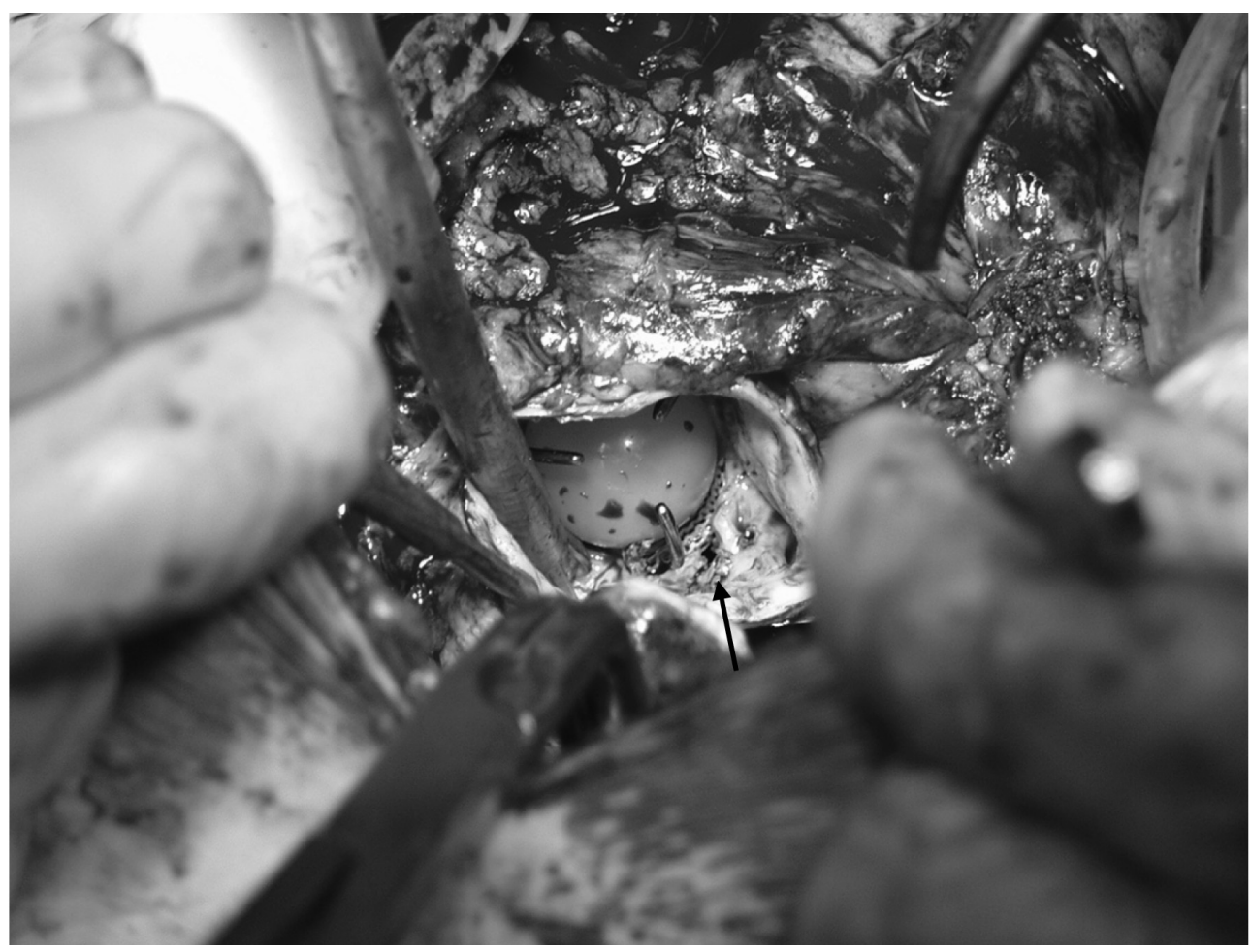

Figure I Intraoperative picture of the modified Smeloff-Cutter caged-ball aortic prosthesis with a paravalvular leakage (arrow). 

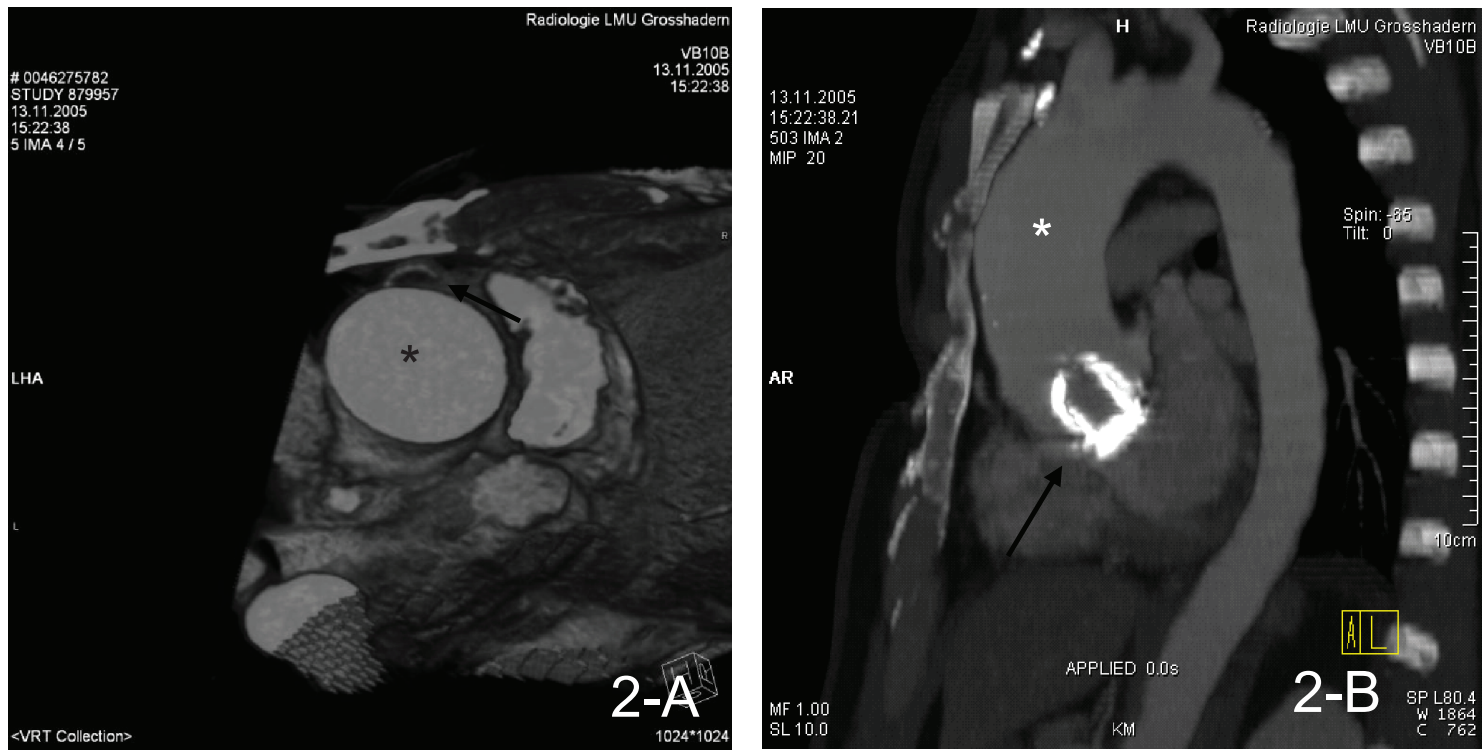

Figure 2 ECG-gated 64-row MSCT with volume rendering technique (VRT) and three-dimensional reconstruction demonstrating the aneurysmatic ascending aorta (*, 2-A, -B), the sternum proximity to the RCA (arrow, 2-A) as well as the prosthetic aortic valve (arrow, 2-B).

Abbreviations: ECG, electrocardiogram; MSCT, multi-slice computed tomography; RCA, right coronary artery.

of surgery was 300 minutes. The patient was extubated the same day, and postoperative course remained without complications.

\section{Discussion}

In re-operative cases, damaging any part of the heart while opening the chest and consecutive emergent femoral cannulation under excessive bleeding and hemodynamic instability is a major disaster and a situation every surgeon wants to prevent. In addition to that, Hepatitis $\mathrm{C}$ virus (HCV) infection remains a real risk for transmission in the operating room, given that no vaccine is available. Our patient suffered from chronic $\mathrm{HCV}$ infection with a high virus load. Postponing the surgery to reduce the virus load was in this case not a valid alternative due to the urgency of this intervention, as the risks of a decompensation due to the aortic insufficiency were too high.

Several standards of infection control were followed to protect the surgical team from blood exposure. The exact rate of transmission of HCV infection in the operating room is not clearly established, but has been identified at about $1.8 \%$ secondary to hollow needle sticks. ${ }^{1}$ Popejoy and colleagues reported that $28 \%$ of surgical procedures had one or more persons in the operating room encounter skin-contact with blood, and one or more percutaneous injuries occurred in $8 \%$ of the cases. ${ }^{2}$ McAdam and colleagues observed a $9.7 \%$ glove perforation rate in their emergency department. ${ }^{3}$ Double gloving, face shields, sleeve reinforcements for the forearms, and trauma boots will reduce the incidence of blood contact. Wires must be handled with great care, blind suturing techniques must be avoided, needles should be removed before tying knots, a "way-station", intended as a place where instruments stay between the surgeon and the nurse, avoids puncture wounds in either direction and most importantly an increased awareness of all sharp instruments is essential. Following the American College of Surgeons' statement on the surgeon and hepatitis, to "utilize the highest standards of infection control and scientifically accepted measures to prevent blood exposure" ${ }^{4}$ we think that, in our case, thorough pre-surgical screening by real-time threedimensional echocardiography and 64-row MSCT resulted in an additional reduction of operative risks for both the patient and the surgical team. Because of the demonstrated close proximity of the RV, the RCA and the aortic aneurysm to the sternum we decided to open the chest with the heart unloaded on CPB, leading to a reasonable 20 minutes longer bypass time, leading, however, to a reduced bleeding and surgical risk.

Health care professionals should be aware that as patients with HIV and chronic Hepatitis B virus or HCV infection live longer because of improved treatment, more of them can be expected to undergo cardiothoracic procedures and every effort, including modern imaging technologies, should be undertaken to prevent transmission of any infectious disease.

\section{Disclosure}

The authors report no conflicts of interest in this work. 


\section{References}

1. Recommendations for prevention and control of hepatitis $\mathrm{C}$ virus $(\mathrm{HCV})$ infection and HCV-related chronic disease. Centers for Disease Control and prevention. MMWR Recomm Rep. 1998;47:1-39.

2. Popejoy SL, Fry DE. Blood contact and exposure in the operating room. Surg Gynecol Obstet. 1991;172:480-483.
3. McAdam TK, McLaughlin RE, McNicholl B. Are we getting the point? Needlestick injuries-an ongoing problem. Int J STD AIDS. 2002;13:453-455.

4. American College of Surgeons. Statement on the surgeon and hepatitis. April 2004. Accessed May 26, 2006. Available from: http://www.facs. org/fellows_info/statements/st-22.html.

\section{Publish your work in this journal}

Therapeutics and Clinical Risk Management is an international, peerreviewed journal of clinical therapeutics and risk management, focusing on concise rapid reporting of clinical studies in all therapeutic areas, outcomes, safety, and programs for the effective, safe, and sustained use of medicines. This journal is indexed on PubMed Central, CAS,
EMBase, Scopus and the Elsevier Bibliographic databases. The manuscript management system is completely online and includes a very quick and fair peer-review system, which is all easy to use. Visit http://www.dovepress.com/testimonials.php to read real quotes from published authors.

Submit your manuscript here: http://www.dovepress.com/therapeutics-and-clinical-risk-management-journal 